\title{
Stellantchasmus falcatus (Digenea: Heterophyidae) in Cambodia: Discovery of Metacercariae in Mullets and Recovery of Adult Flukes in an Experimental Hamster
}

\author{
Jong-Yil Chai ${ }^{1,2}$, Woon-Mok Sohn ${ }^{3, *}$, Byoung-Kuk Na ${ }^{3}$, Hoo-Gn Jeoung ${ }^{2}$, Muth Sinuon ${ }^{4}$, Duong Socheat ${ }^{4}$ \\ ${ }^{1}$ Department of Parasitology and Tropical Medicine, Seoul National University College of Medicine, Seoul 03080, Korea; ${ }^{2}$ Korea Association of \\ Health Promotion, Seoul 07653, Korea; ${ }^{3}$ Department of Parasitology and Tropical Medicine, and Institute of Health Sciences, Gyeongsang National \\ University School of Medicine, Jinju 52727, Korea; ${ }^{4}$ National Center for Parasitology, Entomology and Malaria Control, Phnom Penh, Cambodia
}

\begin{abstract}
Stellantchasmus falcatus (Digenea: Heterophyidae) is first reported from Cambodia through recovery of the metacercariae from mullet fish and adult flukes from an experimentally infected hamster. We purchased 7 mullets, Chelon macrolepis, in a local market of Phnom Penh, Cambodia, and each of them was examined by the artificial digestion method on May 2010. The metacercariae of S. falcatus were detected in all mullets (100\%) examined, and their average density was 177 per fish. They were elliptical, $220 \times 168 \mu \mathrm{m}$ in average size. They were orally infected to an hamster to obtain adult flukes. Adults recovered at day 10 post infection were observed with a light microscope and a scanning electron microscope (SEM). They were small, $450 \times 237 \mu \mathrm{m}$ in average size, had a small oral sucker $(41 \times 50 \mu \mathrm{m})$, subglobular pharynx $(29 \times 21 \mu \mathrm{m})$, slender esophagus $(57 \mu \mathrm{m})$, long and thick-walled expulsor $(119 \times 32 \mu \mathrm{m})$, spherical ovary $(58 \times 69$ $\mu \mathrm{m}$ ), and 2 ovoid testes (right: $117 \times 74 \mu \mathrm{m}$; left: $114 \times 63 \mu \mathrm{m}$ ). Eggs were small, yellow, and $23 \times 12 \mu \mathrm{m}$ in average size. In SEM observations, tegumental spines were densely distributed on the whole tegument, and single small type I sensory papillae were distributed around the lip of oral sucker. The small ventral sucker was dextrally located and had 8 type I sensory papillae on the left margin. It has been first confirmed in the present study that the mullet, C. macrolepis, is playing the role of a second intermediate host of $S$. falcatus in Cambodia.
\end{abstract}

Key words: Stellantchasmus falcatus, mullet, metacercaria, adult, Cambodia

Stellantchasmus falcatus (Digenea: Heterophyidae) is one of the zoonotic intestinal flukes, which has been reported in many Asian-Pacific countries, such as Japan, the Philippines, Hawaii, Palestine, Thailand, Vietnam, and the Republic of Korea (Korea) [1-12]. Several species of fish, such as Mugil cephalus, Liza haematocheila, Acanthogobius flavimanus, Dermogenus pusillus, Xenentodon canciloides, Osphronemus gourami, Cyprinus carpio, and Ctenopharyngodon idella, were reported as the second intermediate hosts and the source of human infections [13-21]. On the other hand, it has been known that some Cambodian people are infected with zoonotic trematodes, including Opisthorchis viverrini [22,23], and several species of fish in Cambodia are infected with

\footnotetext{
- Received 6 April 2016, revised 18 May 2016, accepted 8 June 2016.

*Corresponding author (wmsohn@gnu.ac.kr)

(c) 2016, Korean Society for Parasitology and Tropical Medicine

This is an Open Access article distributed under the terms of the Creative Commons Attribution Non-Commercial License (http://creativecommons.org/licenses/by-nc/4.0) which permits unrestricted non-commercial use, distribution, and reproduction in any medium, provided the original work is properly cited.
}

fishborne zoonotic trematode (FZT) metacercariae [23-26]. However, the metacercariae of $S$. falcatus have not been reported in fish from Cambodia. In addition, adult flukes of $S$. falcatus have never been recorded from the definitive hosts in Cambodia. Therefore, in the present study, we describe the metacercariae of $S$. falcatus from the mullet Chelon macrolepis purchased in a local market of Phnom Penh, Cambodia. We also describe the adult flukes recovered from an experimental hamster.

Total 7 largescale mullets (14.5-17.2 cm in length and 55.5$85.3 \mathrm{~g}$ in weight), C. macrolepis (Fig. 1), were purchased in a local market of Phnom Penh, Cambodia on May 2010. They were transported to the Department of Parasitology and Tropical Medicine, Gyeongsang National University School of Medicine, Jinju, Korea under refrigeration. Individual fish was finely ground with a mortar and a pestle or a grinder, and the ground fish flesh was mixed with artificial gastric juice followed by incubation at $36^{\circ} \mathrm{C}$ for $2 \mathrm{hr}$. The digested material was filtered through $1 \times 1 \mathrm{~mm}$ mesh, and washed with $0.85 \%$ 
saline until the supernatant became clear. The sediment was carefully examined under a stereomicroscope, and then the metacercariae were collected. The metacercariae collected were orally fed to a hamster to obtain adult flukes. Adult flukes were recovered in the small intestines of the hamster at day 10 post infection (PI).

For light microscopic observations, the adult flukes were fixed in $10 \%$ neutral buffered formalin. After washing with distilled water, the specimens were stained with Semichon's acetocarmine,

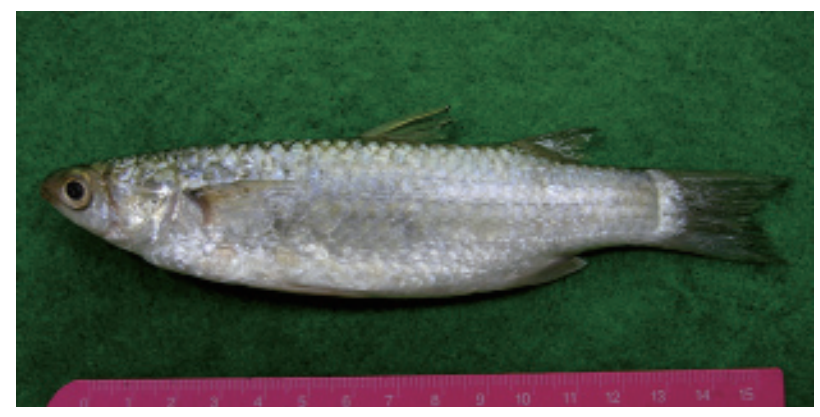

Fig. 1. The largescale mullet, Chelon macrolepis, examined in the present study. followed by dehydration with graded ethanol series $(70 \%, 80 \%$, $90 \%, 95 \%$, and absolute), and cleared with carbol-xylol and xylene. They were mounted in Canada balsam. Some adult flukes were washed with $0.2 \mathrm{M}$ cacodylate buffer ( $\mathrm{pH} 7.2$ ) and fixed with $2.5 \%$ glutaraldehyde for scanning electron microscopy (SEM). They were dehydrated, dried, and mounted on aluminum stubs, followed by coating with gold using a JFC-1100E ion sputtering device (Jeol, Tokyo, Japan). The mounted specimens were observed using a XL-30S SEM (Philips, Amsterdam, The Netherlands) at an accelerating voltage of $20 \mathrm{kV}$. All measurement unit (average) is micrometer $(\mu \mathrm{m})$.

The metacercariae of $S$. falcatus (Fig. 2A) were detected in all of the mullets (100\%) examined. The metacercarial densities were 6-430 (177 in average) per fish. They $(\mathrm{n}=20)$ were elliptical, 195-240 (220) by 138-190 (168) in size. Brownish pigments were scattered in the whole body. The excretory bladder was not obviously seen.

Adults ( $\mathrm{n}=10$; Fig. $2 \mathrm{~B}$ ) were small, oval to pyriform, dorsoventrally flat, 405-510 (450 in average) long and 220-250 (237) wide. Oral sucker subterminal, 38-45 (41) by 43-55 (50). Pharynx subglobular, 25-30 (29) by 13-30 (21). Esopha-
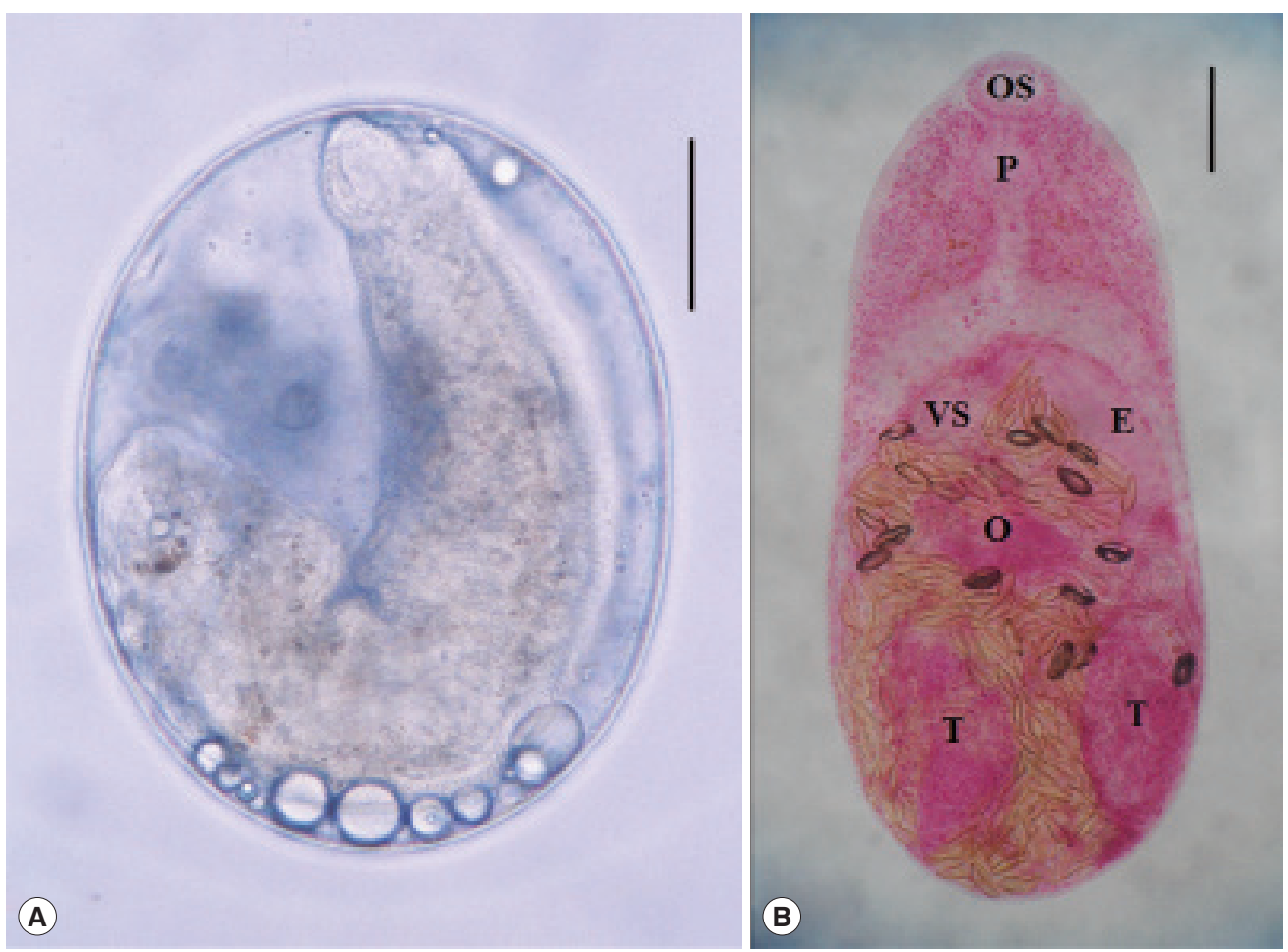

Fig. 2. (A) Stellatchasmus falcatus metacercaria detected in a largescale mullet purchased from a local fish market in Phnom Penh, Cambodia. (B) An adult of Stellatchasmus falcatus (Semichon's acetocarmine stained) recovered from the small intestine of an experimentally infected hamster at 10 days after infection. E, expulsor; O, ovary; OS, oral sucker; P, pharynx; T, testis; VS, ventral sucker. Scale bar $=50 \mu \mathrm{m}$. 
gus slender, 40-65 (57) long. Ventral sucker small. Expulsor long and thick-walled, 105-138 (119) by 30-35 (32). Seminal vesicle saccate. Ovary spherical, 50-75 (58) by 50-88 (69). Two testes ovoid or globular, slightly oblique and widely separated; right 100-138 (117) by 68-80 (74); left 100-125 (114) by 5573 (63). Vitellaria follicular, distributing in the post-ovarian fields. Eggs small, yellow, and 22-24 (23) by 11-13 (12).

In SEM observations, worms were ventrally concave with pointed anterior and rounded posterior ends. Tegumental spines were densely distributed on the whole tegument except on the dorsal side of the posterior $1 / 6$ of the body. They were somewhat sparse in the posterior body (Fig. 3A, B). Single small type I sensory papillae were distributed around the lip of the oral sucker, and grouped type I sensory papillae were presented around the oral sucker (Fig. 3C). The ventral sucker was small, dextrally located, and retained 8 type I sensory papillae on its left margin (Fig. 3D). The dorso-middle surface (the upper square in Fig. 3B) was spinous with numerous wide broom brush-shaped tegumental spines like in the ventral surface and sperms entering into the opening of Laurer's canal (Fig. 3E). The dorso-posterior surface (the lower square in Fig. 3B) was nearly aspinous with only a few small 2-5 tiped tegumental spines (Fig. 3F).

In the present study, it has been confirmed for the first time that the largescale mullet, C. macrolepis, plays the role of a second intermediate host of $S$. falcatus in Cambodia. As the second intermediate hosts of this fluke, several species of brackish water and freshwater fish, including the mullet ( $M$. cephalus and L. haematocheila), goby (A. flavimanus), wrestling halfbeak (D. pusilla), X. canciloides, giant gouramy (O. gourami), common carp (C. carpio), and grass carp (C. idella), have been reported in Japan, Hawaii, China, Korea, Thailand, Viet-
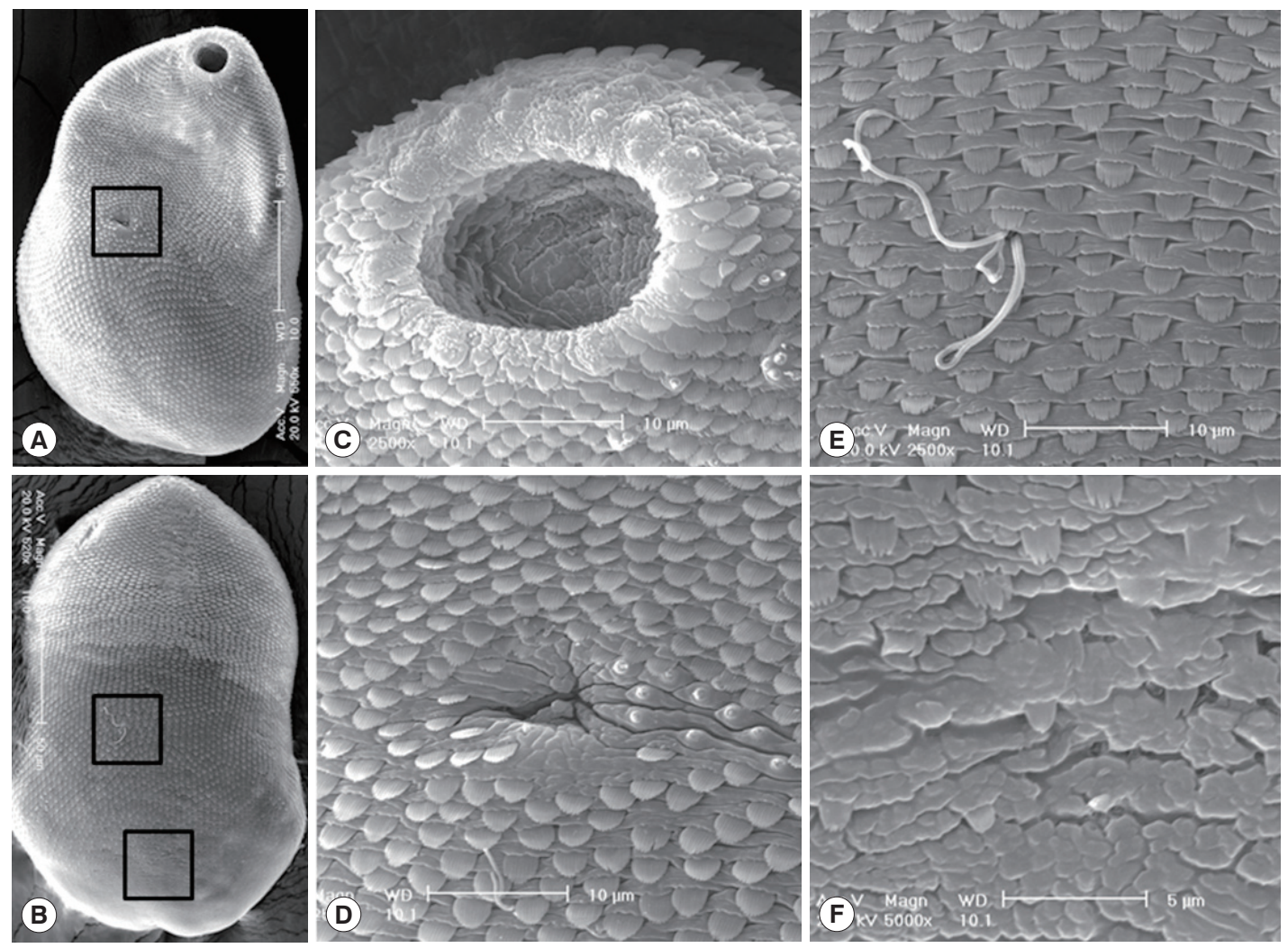

Fig. 3. SEM findings of $S$. falcatus recovered from an experimental hamster. (A) Whole ventral view, showing its concave body with scale-like tegumental spines and 2 suckers, the oral sucker in anterior end and the ventral sucker dextrally located (in the square). (B) Whole dorsal view. The body surface is covered with scale-like tegumental spines except for the surface near posterior end. (C) Tegument around the oral sucker. Numerous small ciliated type I sensory papillae are seen on the dorsal lip and 2-4 grouped type I sensory papillae are observed near the oral sucker. (D) Tegument around the ventral sucker. Ventral sucker is small, dextrally located, and has 8 type I sensory papillae in it's left margin. (E) Tegument on the dorso-middle surface. Numerous broom brush-shaped tegumental spines are compactly distributed and sperms entering into the opening of Laurer's canal. (F) Tegument on the dorso-posterior surface. Tegumental spines here became sparser and less digitated. 
nam, and Lao PDR [13-21]. Among these fish hosts, the mullet is the most frequently reported in various regions of Japan, Hawaii, China, Korea, and Vietnam [13-16,21]. However, the largescale mullet, C. macrolepis, has never been reported as the fish host for $S$. falcatus prior to this study which was done in Cambodia. On the other hand, freshwater fish, D. pusilla, X. canciloides, O. gourami, C. carpio, and C. idella, are known to be the fish hosts of this fluke in Southeast Asian countries, Thailand, Vietnam, and Lao PDR [17-20].

Stellantchasmus was first described with adult flukes obtained from cats experimentally fed the metacercariae from mullets in Japan. The fluke in this genus is characterized by the presence of a slightly deviated ventral sucker to the right side of the body and an elongated sac-like seminal vesicle (expulsor) at the opposite side of the ventral sucker [27]. Until now, total 4 species have been reported in this genus, including the type $S$. falcatus. Chen [28] treated several previously reported species as synonyms of $S$. falcatus [28]. Pearson [29] agreed the opinion of Chen [27], and proposed a new species, S. aspinosus, with an unarmed and modified ventral sucker as a differential character. Later, 2 other species, S. batillans Pearson, 1964 and S. gallinae (Oshmarin, 1971) Pearson and Ow-Yang, 1982, have been reported $[29,30]$.

The metacercariae of $S$. falcatus were $195-240 \times 138-190$ in size and had obscure excretory bladders in the present study. They were somewhat larger than those from mullets in Korea $(150-200 \times 130-190)$ [16], but smaller than those from mullets in Vietnam $(255-330 \times 225-250)$ [21]. The excretory bladder was round in metacercariae from mullets in Korea, but V-shaped in Vietnam. However, their general morphologies were very similar to one another among the 3 geographical isolates of metacercariae. They were commonly elliptical in shape, had a relatively thick and elastic cyst wall, yellowish-brown pigment granules scattered all over the body, a submedian small ventral sucker, and a thick-walled bulb-like expulsor. In adult flukes, there were no differences in their detailed morphologies, which were recovered from experimental animals infected with metacercariae detected in mullets from 3 countries, i.e., Korea, Vietnam, and Cambodia [16,21].

Total 5 species of FZT metacercariae were detected in freshwater fishes from Cambodia, i.e., O. viverrini, Haplorchis pumilio, Haplorchis yokogawai, Centrocestus formosanus, and Procerovum varium [23-25]. However, $S$. falcatus metacercariae were first found in fish from Cambodia. We additionally collected Pygidiopsis metacercariae from the same mullet, which were described as a new species, Pygidiopsis cambodiensis n. sp., with their adults recovered from hamsters experimentally fed the metacercariae [31]. Conclusively, it has been confirmed that the largescale mullet, C. macrolepis, from Cambodia play the role of second intermediate hosts and possibly the sources of human infections with $S$. falcatus as well as $P$. cambodiensis. Trials to detect human infections with these flukes should be performed in Cambodia.

\section{ACKNOWLEDGMENTS}

We thank Jung-A Kim and Hee-Ju Kim, Department of Parasitology and Tropical Medicine, Gyeongsang National University School of Medicine, Jinju, Korea, for their help in fish examinations. We also thank the staff of the Korea Association of Health Promotion, Seoul, the Republic of Korea, who participated in the Korea-Cambodia Cooperation Project on Parasite Control in Cambodia (2006-2011).

\section{CONFLICT OF INTEREST}

The authors declare that they have no conflict of interest related with this article.

\section{REFERENCES}

1. Takahashi S. On the eggs of Stellantchasmus falcatus and Pygidiopsis summus found in human stools. Okayama Igakkai Zasshi 1929; 41: 1502-1513.

2. Kagei N, Oshima T, Ishikawa K, Kihata M. Two cases of human infection with Stellantchasmus falcatus Onji et Nishio, 1915 (Heterophyidae) in Kochi Prefecture. Jpn J Parasitol 1964; 13: 472- 478 .

3. Seo BS, Lee SH, Chai JY, Hong SJ. Studies on intestinal trematodes in Korea XII. Two cases of human infection by Stellantchasmus falcatus. Korean J Parasitol 1984; 22: 43-50.

4. Hong ST, Chai JY, Lee SH. Ten human cases of Fibricola seoulensis infection and mixed one with Stellantchasmus and Metagonimus. Korean J Parasitol 1986; 24: 95-97.

5. Sohn WM, Chai JY, Lee SH. A human case of Stellantchasmus falcatus infection. Korean J Parasitol 1989; 27: 277-279.

6. Radomyos P, Charoenlarp P, Radomyos B, Tungtrongchitr A. Two human cases of Stellantchasmus falcatus (Trematoda, Heterophyidae) infection in Northeastern Thailand. Jpn J Parasitol 1990; 39: 7-11.

7. Son WY, Huh S, Lee SU, Woo HC, Hong SJ. Intestinal trematode infections in the villagers in Koje-myon, Kochang-gun, Kyongs angnam-do, Korea. Korean J Parasitol 1994; 32: 149-155.

8. Chai JY, Song TE, Han ET, Guk SM, Park YK, Choi MH, Lee SH. 
Two endemic foci of heterophyids and other intestinal fluke infections in southern and western coastal areas in Korea. Korean J Parasitol 1998; 36: 155-161.

9. Hong SJ. A human case of Stellantchasmus falcatus infection in Korea. Korean J Parasitol 2000; 38(1): 25-27.

10. Park JH, Kim JL, Shin EH, Guk SM, Park YK, Chai JY. 2007. A new endemic focus of Heterophyes nocens and other heterophyid infections in a coastal area of Gangin-gun, Jeollanam-do. Korean J Parasitol 2007; 45: 33-38.

11. Dung TD, De NV, Waikagul J, Dalsgaard A, Chai JY, Sohn WM, Murrell KD. Fishborne zoonotic intestinal trematodes, Vietnam. Emerg Infect Dis 2007; 13: 1,828-1,833.

12. Cho SH, Cho PY, Lee DM, Kim TS, Kim IS, Hwang EJ, Na BK, Sohn WM. Epidemiological survey on the infection of intestinal flukes in residents of Muan-gun, Jeollanam-do, the Republic of Korea. Korean J Parasitol 2010; 48: 133-138.

13. Onji Y, Nisho T. A monograph of intestinal trematodes. Chiba Igakkai Zasshi 1924; 2: 113-161 (in Japanese).

14. Alicata JE, Schattenburg OL. A case of intestinal heterophyidiasis of man in Hawaii. J Am Med Ass 1938; 110: 1100-1101.

15. Kobayashi H. Studies on the trematodea in Hainan Island, South China and Vietnam (French Indochina). Reports of Scientifical works by H. Kobayashi, 1968, pp 155-251.

16. Chai JY, Sohn WM. Identification of Stellantchasmus falcatus metacercariae encysted in mullets in Korea. Korean J Parasitol 1988; 26: 65-68.

17. Ditrich O, Scholz T, Giboda M. Occurrence of some medically important flukes (Trematoda: Opisthorchiidae and Heterophyidae) in Nam Ngum water reservoir, Laos. Southeast Asian J Trop Med Public Health 1990; 21: 482-488.

18. Sripalwit P, Wongsawad C, Chai JY, Anuntalabhochai S, Rojanapaibul A. 2003. Investigation of Stellantchasmus falcatus metacercariae in half-beaked fish, Dermogenus pusillus from four districts of Chiang Mai Province, Thailand. Southeast Asian J Trop Med Public Health 2003; 34: 281-285.

19. Thien PC, Dalsgaard A, Bui NT, Olsen A, Murrell KD. Prevalence of fishborne zoonotic parasites in important cultured fish species in the Mekong Delta, Vietnam. Parasitol Res 2007; 101: 1277-1284.

20. Chi TTK, Dalsgaard A, Turnbull JF, Tuan PA, Murrell KD. Prevalence of zoonotic trematodes in fish from a Vietnamese fish farm- ing community. J Parasitol 2008; 94: 423-428.

21. Chai JY, De NV, Sohn WM. Foodborne trematode metacercariae in fish from northern Vietnam and their adults recovered from experimental hamsters. Korean J Parasitol 2012; 50: 317-325.

22. Yong TS, Shin EH, Chai JY, Sohn WM, Eom KS, Lee DM, Park K, Jeong HG, Hoang EH, Lee YH, Woo HJ, Lee JH, Kang SI, Cha JK, Lee $\mathrm{KH}$, Yoon $\mathrm{CH}$, Sinuon M, Socheat D. High prevalence of Opisthorchis viverrini infection in a riparian population in Takeo Province, Cambodia. Korean J Parasitol 2012; 50: 173-176.

23. Chai JY, Sohn WM, Na BK, Yong TS, Eom KS, Yoon CH, Hoang $\mathrm{EH}$, Jeoung HG, Socheat D. Zoonotic trematode metacercariae in fish from Phnom Penh and Pursat, Cambodia. Korean J Parasitol 2014; 52: 35-40.

24. Sohn WM, Yong TS, Eom KS, Pyo, KH, Lee, MY, Lim HM, Choe SJ, Jeong HG, Sinuon M, Socheat D, Chai JY. Prevalence of Opisthorchis viverrini infection in humans and fish in Kratie Province, Cambodia. Acta Trop 2012; 124: 215-220.

25. Sohn WM, Shin EH, Yong TS, Eom KS, Jeong HG, Sinuon M, Socheat D, Chai JY. Adult Opisthorchis viverrini flukes in humans, Takeo, Cambodia. Emerg Infect Dis 2011; 17: 1302-1304.

26. Touch S, Komalamisra C, Radomyos P, Waikagul J. Discovery of Opisthorchis viverrini metacercariae in freshwater fish in southern Cambodia. Acta Trop 2009; 111: 108-113.

27. Onji Y, T Nishio. On the trematodes whose intermediate host is brackish water fishes. Chiba Igaku Semmon Gakko Zasshi 1916; 81, 82: 229-249.

28. Chen HT. Stictodora manilensis and Stellantchasmus falcatus from Hong Kong, with a note on the validity of other species of the two genera (Trematoda: Heterophyidae). Lingnan Sci J 1951; 23: 165-175.

29. Pearson JC. A revision of the subfamily Haplorchinae Loose, 1899 (Trematoda: Heterophyidae) I. The Haplorchis group. Parasitology 1964; 54: 601-676.

30. Pearson JC, Ow-Yang CK. New species of Haplorchis from Southeast Asia, together with keys to the Haplorchis-group of heterophyid trematodes of the region. Southeast Asian J Trop Med Public Health 1982; 13: 35-60.

31. Sohn WM, Kim DG, Jung BK, Cho J, Chai JY. Pygidiopsis cambodiensis n. sp. (Digenea: Heterophyidae) from experimental hamsters infected with metacercariae in mullets from Cambodia. Parasitol Res 2016; 115: 123-130. 